\title{
Sensitivity Analysis for Identifying the Critical Productivity Factors of Container Terminals
}

\author{
Bo Lu1,* - Nam Kyu Park² \\ 1 Dalian University, Institute of Electronic Commerce and Modern Logistics, China \\ 2 Tongmyong University, School of Port and Logistics, South Korea
}

With the rapid expansion of international trade, a distinctive feature of the contemporary container terminal industry is that competition has become more intense. If container terminal managers can gain a proper appreciation of their various productivity factors, they may be able to identify which factors have a more positive influence on productivity. The core of sensitivity analysis for evaluating terminal productivity is to remove input variables one by one, then re-estimate the correlation between productivity and investment. From this perspective, sensitivity analysis provides a more appropriate benchmark for identifying which factors are more critical for productivity improvement. This analysis has been variously studied utilizing either Data Envelopment Analysis or Regression Analysis. Given the strengths associated with these two analyses, this paper applies both approaches to the same set of data for 28 major East Asian container terminals and compares the results of the efficiency. The results of this study can provide a useful reference to port managers for developing improvement strategies.

Keywords: data envelopment analysis, regression analysis, sensitivity analysis, container terminal productivity

\section{INTRODUCTION}

A distinctive feature of the contemporary container port industry is that competition has become fiercer than ever [1]. Improving productivity sufficiently to accommodate a large portion of the anticipated increase in container traffic presents a particular challenge to terminal operators and port authorities.

As the demand for international trade and global logistic services continues to increase, to remain competitive [2], in [3] the authors claimed that container terminals have to invest heavily in sophisticated equipment or in dredging channels to accommodate the most advanced and largest container ships. It is necessary to note that pure physical expansion is constrained by a limited supply of available land, especially for urban-centric ports, and escalating environmental concerns [4]. In addition, excessive and inappropriate investment also can induce inefficiency and the wasting of resources. In this context, expanding port capacity by improving the productivity of terminal facilities and exploring the critical factors affecting the productivity appears to be a viable solution [5].

For a container terminal, productivity performance makes a significant contribution to the terminal's survival prospects and competitive advantage [6]. Traditionally, the performance of a container terminal has been evaluated with numerous attempts at calculating and seeking to improve or optimize the operational productivity of cargo handling at the berth and container yard [7]. A conceptual framework for analysing the outcomes of potential competitive strategies and their expected payoffs for container terminal operators in the container handling industry is presented in [8]. It is based on the integration of Bowley's linear model of aggregate demand of product differentiation with Porter's "Diamond" model. The authors developed ten competitive strategies for container terminal operators in order to present a theoretical scenario of two competing container terminal operators to exemplify the effectiveness of these strategies in terms of the number of TEUs handled, prices charged, and profits earned.

The data envelopment analysis (DEA) methodology has been applied to the evaluation of container terminal performance in the literature. For example, in [9] the first work to advocate the application of the DEA technique to the terminals' context is presented; it remains a purely theoretical exposition, rather than a genuine application. DEA window analysis using panel data relating to the eight container ports in Japan is conducted in [10]. In [1], DEA-CCR (Charnes Cooper and Rhodes model) and DEA-Additive models are used to analyse the efficiency of four Australian and 12 other international container ports. Applying DEA to estimate the relative efficiency of a sample of Portuguese and Greek seaports is given in [11]. DEA and stochastic frontier analysis have been used to study the efficiency of the world's largest container ports and compare the results obtained in [3]. In [12], the relevance of DEA was analysed to estimate the productive efficiency of the container port industry. Available DEA panel data approaches were applied to a sample of 25 leading container ports and evaluated in [13]. 
In [14], five models of DEA were applied to identify trends in port efficiency of major container ports in the Asia-Pacific region. The impact of different groups on the efficiency of 28 container ports from 12 countries and regions in Asia was studied in [15]. In [16], the DEA method has been proven to be a suitable tool for evaluating performance with multiple inputs and outputs in respect to 77 global container ports. It was found that the number of berths and the capital deployed are the most sensitive measures impacting the performance of most container ports.

In contrast with previous investigations, this study aims to explore the relationship among productivity indicators of container terminals and determine which factors have a stronger impact on productivity. Regression analysis (RA) is primarily applied to analyse the relationship between one dependent variable and several independent variables. Here, we apply and extend some of the papers in which authors introduced a methodology that incorporates a new variable into the regression analysis that captures the unique weighting of each comparable unit, [17] to [20]. In [17], the different models (DEA and RA) were used in various combinations to determine efficiency estimation and evaluation. The relative merits of DEA and RA in assessments of the comparative efficiencies of organizational units were considered in [18]. In [19], the major differences between RA and DEA were identified, and their appropriateness as a primary means for assessing relative efficiency in the context of regulation with an application to the water industry were evaluated. A methodology that includes a new independent variable, the comparable unit's DEA relative efficiency, into the RA is applied in [20].

From an overall perspective, in this paper, the sensitivity analysis method provides a more appropriate benchmark for identifying which factors are more responsible for the fluctuations in productivity of container terminal by removing the input variables one by one, and then re-estimating the correlation between productivity and investment. Sensitivity analysis has been studied, utilizing either DEA or RA. However, the existing literature reveals a lack of empirical evidence in relation to the comparative effectiveness of sensitivity analysis in an application to the port industry. This paper aims to fill this gap by applying the two approaches to analyse container terminal productivity.

The paper is structured as follows. The descriptions of DEA-CCR and RA with research procedure are given in Section 1. Section 2 provides the data collection, efficiency analyses and standardization of variables. Empirical results and sensitivity analyses of DEA-CCR and RA are presented in Section 3. The major differences between RA and DEA-CCR with the relative merits are considered in Section 4. Finally, conclusions are drawn in Section 5.

\section{RESEARCH METHODOLOGIES}

\subsection{Data Envelopment Analysis (CCR Model)}

In order to describe the research methodologies for determining critical factors at container terminals, the first step is to explain the proposed analyses. DEA is a non-parametric method of measuring the efficiency of a decision-making unit (DMU). It was applied into operations research, where authors introduced the CCR model [21]. The evaluation of container terminal efficiency using the DEA-CCR method begins by choosing appropriate input and output variables.

Like in [3] but applying the expressions to container terminal efficiency, let the inputs be $x_{k}=\left(x_{1 k}, x_{2 k}, x_{M k}\right) \in R_{+}^{M}$ (in this case: berth length, quay crane, yard area, terminal crane and yard tractor) to produce outputs $y_{k}=\left(y_{1 k}, y_{2 k}, y_{N k}\right) \in R_{+}^{N}$ denoted as throughput per berth. The row vectors $x_{k}$ and $y_{k}$ forms the $k^{\text {th }}$ rows of the data matrices $X$ and $Y$, respectively. Let $\lambda_{k}=\left(\lambda_{1}, \lambda_{2}, \lambda_{k}\right) \in R_{+}^{K}$ be a non-negative vector that forms the linear combinations of the $K$ container terminals. Finally, let $e=(1,1, \ldots, 1)$ be a suitably dimensioned vector of unity values.

In this study, the output-oriented DEA-CCR model seeks to maximize the proportional increase in output variables while remaining within the production possibility set. An output-oriented efficiency measurement problem can be written as a series of $K$ linear programming envelopment problems, as shown in Eqs. (1) to (4) [3] and [12].

$$
\max _{U, \lambda} U
$$

subject to

$$
\begin{gathered}
U_{y}^{\prime}-y^{\prime} \lambda \leq 0, \\
X^{\prime} \lambda-x^{\prime} k \leq 0, \\
\lambda \geq 0 \text { (DEA-CCR). }
\end{gathered}
$$

The combination of equations from Eqs. (1) to (4) form the DEA-CCR model. Because the CCR model gives a value of 1 for all efficient DMUs, it is unable to establish any further distinctions among the efficient DMUs. 
In this study, the DEA-CCR model conducts the efficiency value analysis first when efficiency is less than 1; this means that the efficiency of the inputs and outputs variables are not appropriate and that it is necessary to decrease inputs or increase outputs. However, when the scale efficiency is less than 1 it indicates inefficiency, meaning that the operational scale is not achieving an optimal value and that the operational scale should be enlarged or reduced (based on the return to scale). In addition, it is possible to compare the technical efficiency value with the scale efficiency value, with the smaller value of the two, indicating the major cause of inefficiency. Furthermore, the slack variable analysis handles the utilization rate of input and output variables. It does this by assessing how to improve the operational performance of inefficient DMUs by indicating how many inputs to decrease, and/or how many outputs to increase, so as to render the inefficient DMUs efficient. Finally, the sensitivity analysis removes the input variables one by one, and then re-estimates the aggregate efficiency. This facilitates an overall understanding of which input variables are more critical for efficiency improvement [16]. In summary, the flow process of multiple DEA-CCR analyses can be depicted as shown in Fig. 1.

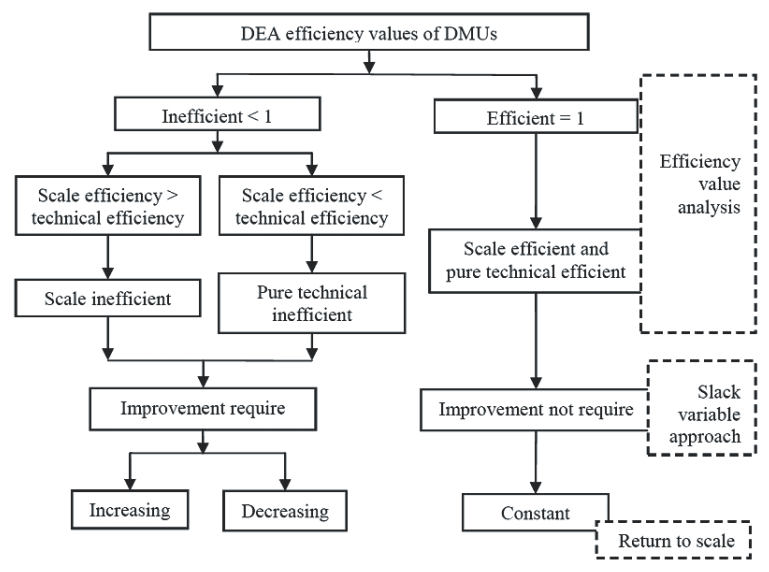

Fig. 1. Flow process of DEA-CCR model

\subsection{Regression Analysis (RA)}

The second research method proposed in this study is RA. It is used to determine which among the independent variables are related to the dependent variable, and to explore the forms of these relationships. More specifically, it aids in understanding how the typical value of the dependent variable changes when any one of the independent variables is varied, while the other independent variables are held fixed. In restricted circumstances, RA can be used to infer causal relationships between the independent and dependent variables. However, it is also widely used for prediction and forecasting, [22] and [23].

For this study, multiple linear regression analysis is adopted to test the hypothesized inter-relationship between the dependent performance variable and the independent variables that relate to the productivity of container terminals, [4] and [5]. This study tries two methods: Enter and Backward, of which one is selected as the best method for results (see Fig. 2). First, it is necessary to estimate the model with all the predictors. Second, this research method follows the inputs of all of the selected variables, then estimates all the predictors, using the enter method and backward elimination method. The backward elimination method is used with settings at $5 \%$ significance levels. If all the regression coefficients are significant, the procedure stops; otherwise, those with the smallest significance will be eliminated from the model. The procedure finally stops when all the regression coefficients are significant. Finally, analysing and explaining the regression results, some tests (R-squared and Adjusted R-squared, ANOVA and coefficient analysis) are conducted on each independent variable and F-test for the overall regression (see Fig. 2).

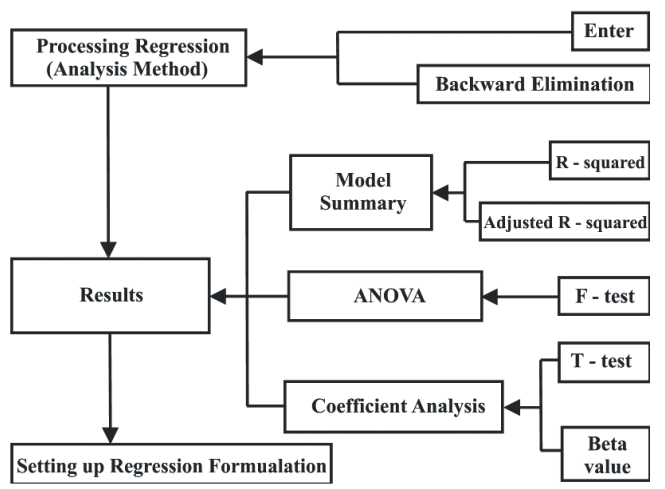

Fig. 2. Regression analysis model

The regression formulation based on parameters $\beta_{0}, \beta_{1}, \ldots, \beta_{r-1}$ with independent variables $x_{1}, \ldots, x_{r-1}$ for $n$ container terminals can be set up as follows:

$$
y_{i}=\beta_{0}+\beta_{1} x_{1}+\ldots+\beta_{r-1} x_{r-1}+\varepsilon_{r}, \quad r=1, \ldots, n .
$$

\subsection{Research Procedure}

The research procedure of this study is summarized in Fig. 3 where the application of the proposed methods 
is shown. On the basis of the literature review, survey and interviews, we eliminate the duplication factors so the initial input/independent variables can be chosen. Then, we assume a database for the 28 East Asian container terminals for which we decide the input/ independent variables and output/dependent variables. After the collection of data, we apply DEA-CCR and RA by selecting the output/dependent variable. Consequently, sensitivity analysis is performed to compare the obtained results from both methods. In such a manner, we identify the critical factors at container terminals.

This paper has two objectives. In the first, we propose the standardization of variables in order to constitute the accurate platform for the second objective. Moreover, definitions of variables should highlight the processes at container terminals and the factors impacting productivity. The second objective is to apply the two research methods to estimate the critical factors. This study represents a good starting point for identifying the sources of inefficiency and proposes services for improving operational performances at container terminals.

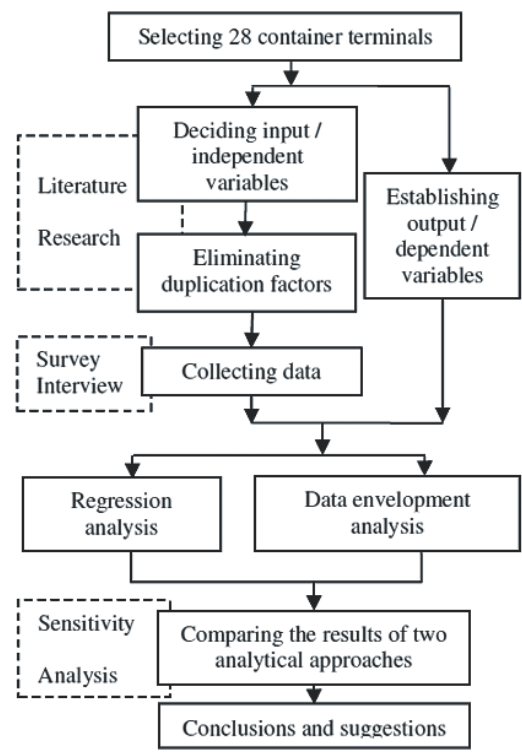

Fig. 3. Application of research methods

2 EFFICIENCY ANALYSES AND STANDARDIZATION OF VARIABLES

\subsection{Data Collection}

The first step towards conducting the productivity of container terminals is to define the port performance characteristics based on the combination of productivity factors (inputs) and then to highlight the outputs. Thus, many critical factors that relate to the terminal operation are to be considered. The sample comprises 28 East Asian major container terminals in 2008. The size of the sample is determined as a function of data availability and is more suitable for comparison [4] to [7].

The productivity indicator of this paper is assumed to be the annual throughput per berth. It is noteworthy that this study defines input/independent and output/dependent variables of each container terminal at the level of the berth. Accordingly, the standardization of variables is denoted as input/ independent variables per berth and output/dependent variables per berth. The data collection of the included container terminals is summarized in Table 1, [4] to [7]. The list of standardized input/independent variables includes: size of yard area (YA), number of quay cranes $(\mathrm{QC})$, terminal cranes (TC), yard tractors (YT) and berth length (BL). Throughput is denoted as a standardized output/dependent variable.

\subsection{Definitions of Variables}

Defining the objectives of container terminals is most important when determining the variables for efficiency measurement, [3]. In our paper, the objective is to maximize the throughput per berth; employment or any information on the equipment and count it as an input/independent variable. The variables should serve to reflect the existence of critical factors at container terminals. In this paper, the main objective is assumed to be the verification and maximization of terminal productivity. According to previously investigated papers ([4] to [7] and [24]), we chose the variables listed in Table 1 for both analyses: DEA-CCR and RA.

On the basis of efficient use of infrastructure and facilities, the previously mentioned independent variables seem to be the most suitable factors to incorporate into the models as input variables. There are some other factors that can be included in this analysis, such as crane operating hours, equipment age and maintenance etc., but they have not been included in this study. The variables should reflect the actual objectives and process of container terminal production as accurately as possible. The importance, difficulties and potential impact of variable definition can be found in [24].

Before defining variables at container terminals, we should incorporate them into the model as input/ independent variables: length of berth, number of quay cranes, size of yard area, number of yard cranes, 
Table 1. Data statistics

\begin{tabular}{|c|c|c|c|c|c|c|}
\hline Variables & $\begin{array}{c}\text { Yard } \\
\text { Area/ } \\
\text { Berth } \\
\text { [ha] }\end{array}$ & $\begin{array}{c}\text { Quay } \\
\text { Crane/ } \\
\text { Berth } \\
\text { (number) }\end{array}$ & $\begin{array}{c}\text { Terminal } \\
\text { Crane/ } \\
\text { Berth } \\
\text { (number) }\end{array}$ & $\begin{array}{c}\text { Yard } \\
\text { Tractor/ } \\
\text { Berth } \\
\text { (number) }\end{array}$ & $\begin{array}{l}\text { Berth } \\
\text { Length/ } \\
\text { Berth } \\
{[\mathrm{m}]}\end{array}$ & $\begin{array}{c}\text { Throughput/ } \\
\text { Berth } \\
\text { (TEU) }\end{array}$ \\
\hline HIT - Hongkong International Terminal in port of Hong Kong & 15.0 & 4.0 & 16.0 & 37.5 & 325 & 877000 \\
\hline Shekou - Shekou Container Terminal in port of Shenzhen & 13.2 & 4.3 & 15.1 & 27.7 & 301 & 817143 \\
\hline COSCO - COSCO-HIT Container Terminal & 20.0 & 3.6 & 11.2 & 20.4 & 360 & 700000 \\
\hline DPI - DPI Container Terminal & 17.3 & 4.1 & 10.5 & 23.3 & 288 & 700000 \\
\hline BICT - Busan International Container Terminal, & 9.3 & 4.1 & 11.8 & 23.3 & 377 & 692083 \\
\hline CS-4 - Chuanshan Container Terminal Phase 4 & 13.8 & 4.1 & 12.0 & 23.3 & 306 & 655556 \\
\hline MTL - Hongkong Modern Terminal in port of Hong Kong & 14.9 & 4.0 & 13.0 & 23.0 & 311 & 650570 \\
\hline PCTC - Pyeongtaek Container Terminal in port of Pyeongtaek & 16.8 & 4.9 & 14.0 & 30.7 & 275 & 640000 \\
\hline NBCT - Ningbo Container Terminal in port of Ningbo & 14.9 & 3.5 & 16.0 & 17.0 & 342 & 632997 \\
\hline HBCT - Hutchison Busan Container Terminal & 25.2 & 3.3 & 10.7 & 16.7 & 340 & 600000 \\
\hline KX3-1 - KOREX Phase 3-1 Container Terminal in port of Gwangyang & 17.5 & 4.0 & 14.5 & 27.5 & 317 & 600000 \\
\hline Chiwan - Chiwan Container Terminal & 16.7 & 4.0 & 8.0 & 50.0 & 287 & 589000 \\
\hline KBCT - Korea Express Busan Container Terminal in port of Busan & 14.3 & 4.0 & 10.0 & 30.0 & 251 & 588000 \\
\hline ACT - Asia Container Terminal & 22.9 & 2.8 & 9.2 & 14.6 & 321 & 468353 \\
\hline HGCT - Hutchison Gamman Container Terminal & 12.9 & 2.8 & 6.8 & 12.6 & 319 & 420594 \\
\hline DPCT - Dongbu Pusan Container Terminal & 12.3 & 2.8 & 10.8 & 14.4 & 280 & 409165 \\
\hline NBSCT - Ningbo Second Container Terminal in port of Ningbo & 21.0 & 3.0 & 8.0 & 12.0 & 330 & 403603 \\
\hline Hanjin - Busan Hanjin Container Terminal & 9.6 & 2.0 & 6.0 & 10.0 & 311 & 355991 \\
\hline Yantian - Yantian Container Terminal in port of Shenzhen & 37.2 & 3.0 & 8.0 & 15.0 & 353 & 333333 \\
\hline ICT - Incheon Container Terminal in Incheon & 12.3 & 3.3 & 10.0 & 16.0 & 293 & 284868 \\
\hline Nansha - Nansha container Terminal in port of Guangzhou & 7.4 & 2.5 & 6.5 & 11.5 & 232 & 279569 \\
\hline JUCT - Jeong-il Ulsan Container Terminal in port of Ulsan & 6.9 & 3.0 & 6.5 & 7.0 & 325 & 172448 \\
\hline UTC - Uam Container Terminal in port of Busan & 8.4 & 3.0 & 7.0 & 7.0 & 301 & 169952 \\
\hline DBE2-1 - Gwangyang DBE Phase 2-1 & 20.7 & 2.0 & 5.0 & 15.0 & 360 & 166371 \\
\hline KIT2-2 - Korea International Terminal Phase 2-2 in port of Gwangyang & 21.0 & 2.0 & 6.0 & 15.0 & 288 & 124590 \\
\hline HKTL - Hutchison Kwangyang Terminal & 21.0 & 2.5 & 8.5 & 11.5 & 377 & 76120 \\
\hline GICT1 - Gwangyang International Container Terminal Phase 1 & 17.6 & 2.0 & 3.8 & 4.0 & 306 & 51638 \\
\hline SGCT - Sun Gwang Container Terminal in Incheon & 12.2 & 1.5 & 3.5 & 4.0 & 311 & 14772 \\
\hline Average & 16.2 & 3.2 & 9.6 & 18.6 & 310 & 445490 \\
\hline
\end{tabular}

and number of yard tractors per berth as summarized in Fig. 4. On the other side, throughput per berth is in function of previously mentioned variables; as observed in the literature, this is the most important and widely accepted indicator of terminal productivity. It is the primary basis on which container terminals are compared. Container throughput is the most appropriate and analytically tractable indicator of the effectiveness of productivity.

From the perspective of the first method, DEACCR provides the minimization of the use of inputs and maximization of the outputs. It is possible to acquire a variety of analytical results about the productivity efficiency for 28 container terminals. This procedure first identifies efficient container terminals and ranks the sequence of them, then finds the reasons the others are inefficient. This is followed by the identification of the potential areas of improvement for inefficient terminals by applying the slack variable method. Finally, by comparing the efficiency scores between the container terminals, the results can identify which input or output variables are more critical to the models.

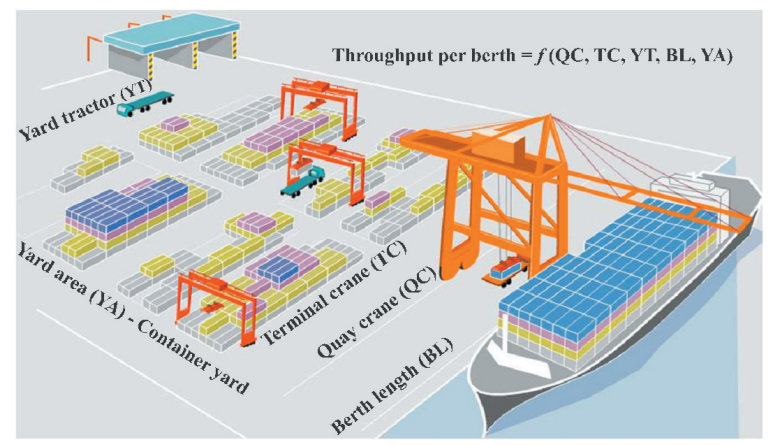

Fig. 4. Variables at container terminal 
However, before utilizing the RA, it is necessary to be aware that all of the collected factors cannot be handled as dependent and independent variables. The possibility for duplication exists among the initial factors and non-linear correlation between dependent and independent variables. However, considering these circumstances first is required to establish the variables pre-processing model.

\section{EMPIRICAL RESULTS}

\subsection{DEA-CCR Model Efficiency Results}

Solver-EMS version 1.3 software is employed to provide the DEA-CCR model results. It is used to analyse the efficiency of the chosen container terminals. Empirical results derived from the first model are presented in Table 2. On the basis of five input variables, efficiency scores are drawn in the first column while ranking is shown in the last column.
According to this table, nine container terminals are efficient because their efficiency scores are equal to 1 . Otherwise, the results in bold mean the lowest value of five variables per terminal indicate they were relatively inefficient terminals. For instance, if we consider the Hanjin container terminal, the critical input is YT with a value of 0.69 and according to efficiency score, it ranks $14^{\text {th }}$ place. There are three terminals that rank first place (Shekou, COSCO and CS-4) while the last ranking is presented for SGCT container terminal in Incheon port.

Next is the identification of critical factors for each terminal. It is important to note that we have included four different ports in China and five in the Republic of Korea. Each port includes one or more container terminals as follows: five container terminals (ACT, COSCO, DPI, HIT and MTL) are located in the port of Hong Kong; seven (DPCT, BICT, HBCT, HGCT, KBCT, UTC and Hanjin) in the port of Busan; three (Chiwan, Shekou and Yantian) in the

Table 2. Empirical results derived from DEA-CCR model

\begin{tabular}{|c|c|c|c|c|c|c|c|}
\hline Terminal & $\begin{array}{c}\text { Efficiency } \\
\text { Scores }\end{array}$ & $\begin{array}{l}\text { Yard Area/ } \\
\text { Berth }\end{array}$ & $\begin{array}{l}\text { Quay Crane/ } \\
\text { Berth }\end{array}$ & $\begin{array}{c}\text { Terminal Crane/ } \\
\text { Berth }\end{array}$ & $\begin{array}{l}\text { Yard Tractor/ } \\
\text { Berth }\end{array}$ & $\begin{array}{l}\text { Berth Length/ } \\
\text { Berth }\end{array}$ & Ranking \\
\hline HIT & 1 & 0.96 & 1 & 1 & 1 & 1 & 3 \\
\hline Shekou & 1 & 1 & 1 & 1 & 1 & 1 & 1 \\
\hline $\operatorname{cosco}$ & 1 & 1 & 1 & 1 & 1 & 1 & 1 \\
\hline DPI & 1 & 1 & 1 & 0.71 & 1 & 1 & 13 \\
\hline BICT & 1 & 1 & 1 & 1 & 0.83 & 1 & 10 \\
\hline CS-4 & 1 & 1 & 1 & 1 & 1 & 1 & 1 \\
\hline MTL & 1 & 1 & 1 & 1 & 0.97 & 1 & 2 \\
\hline PCTC & 1 & 1 & 1 & 1 & 0.95 & 1 & 4 \\
\hline NBCT & 1 & 1 & 1 & 1 & 0.92 & 1 & 5 \\
\hline $\mathrm{HBCT}$ & 0.98 & 0.98 & 0.98 & 0.9 & 0.91 & 0.98 & 6 \\
\hline KX3-1 & 0.93 & 0.93 & 0.93 & 0.9 & 0.77 & 0.93 & 11 \\
\hline Chiwan & 0.91 & 0.86 & 0.91 & 0.88 & 0.9 & 0.91 & 7 \\
\hline KBCT & 0.9 & 0.9 & 0.9 & 0.9 & 0.84 & 0.9 & 9 \\
\hline $\mathrm{ACT}$ & 0.9 & 0.87 & 0.9 & 0.73 & 0.9 & 0.9 & 12 \\
\hline HGCT & 0.89 & 0.87 & 0.88 & 0.88 & 0.85 & 0.89 & 8 \\
\hline DPCT & 0.8 & 0.79 & 0.8 & 0.79 & 0.68 & 0.8 & 15 \\
\hline NBSCT & 0.78 & 0.78 & 0.76 & 0.78 & 0.73 & 0.75 & 12 \\
\hline Hanjin & 0.75 & 0.7 & 0.75 & 0.72 & 0.69 & 0.75 & 14 \\
\hline Yantian & 0.74 & 0.71 & 0.73 & 0.69 & 0.74 & 0.74 & 14 \\
\hline ICT & 0.66 & 0.66 & 0.66 & 0.66 & 0.43 & 0.66 & 18 \\
\hline Nansha & 0.66 & 0.66 & 0.66 & 0.61 & 0.63 & 0.66 & 16 \\
\hline JUCT & 0.65 & 0.65 & 0.65 & 0.65 & 0.38 & 0.65 & 20 \\
\hline UTC & 0.52 & 0.5 & 0.52 & 0.5 & 0.47 & 0.52 & 17 \\
\hline DBE2-1 & 0.49 & 0.49 & 0.49 & 0.4 & 0.49 & 0.49 & 19 \\
\hline KIT2-2 & 0.35 & 0.35 & 0.35 & 0.35 & 0.19 & 0.35 & 22 \\
\hline HKTL & 0.33 & 0.33 & 0.31 & 0.3 & 0.33 & 0.33 & 21 \\
\hline GICT1 & 0.18 & 0.18 & 0.18 & 0.18 & 0.15 & 0.18 & 23 \\
\hline SGCT & 0.1 & 0.1 & 0.1 & 0.1 & 0.06 & 0.1 & 24 \\
\hline
\end{tabular}


port of Shenzhen; three (CS-4, NBCT and NBSCT) in the port of Ningbo; five (DBE2-1, GICT1, HKTL, KX3-1 and KIT2-2) in the port of Gwangyang; two (SGCT and ICT) in the port of Incheon; and one each (Nansha, JUCT and PCTC) in the ports of Guangzhou, Ulsan and Pyeongtaek.

In Table 3, the number of critical factors for each port is given based on the results in bold from Table 2. We have performed an analysis of all nine ports separately to determine their characteristics. For example, Hong Kong's container terminals have the most critical factor TC while no port has indicated BL as being a critical factor at container terminals. The statistics show that YT is the most frequent critical factor in 16 container terminals, which is $57 \%$ of the 28 considered terminals. TC is the second critical factor with $25 \%$ while QC occupies third place with $11 \%$ and YA with $7 \%$. Similarly, according to [16], we state that the number of yard tractors per berth is the major capital input in port operations. The efficiency of a port is the next factor to determine. Therefore, the highest average efficiency is provided by the container terminal in Pyeongtaek, which yields 0.99, while the lowest efficiency is reached in the Incheon container terminal at 0.353 .

Port efficiency statistics for each port are shown in Table 4. The main gap is between container terminals Shekou, COSCO and CS-4 with an efficiency of 1 on one side and on the other SGCT, which has one tenth the efficiency. Therefore, according to DEA-CCR analysis, we can conclude that Hong Kong, Shenzhen and Ningbo have the most efficient container terminals.

\subsection{RA Models Efficiency Results}

Regression models are statistical models that have the advantages of precisely analysing the relationship between one dependent variable and several independent variables, and identifying which factors have a stronger impact on the productivity of container terminal. Regression models also enable the relationships to be explored. The Solver-SPSS software is employed to provide RA model results. Independent variables (the same as input variables for DEA-CCR model) are established by extracting the whole major factors that have a relationship with productivity and the normalization process, which consists of three steps. After that, the interrelationship between independent variables and the dependent variable (throughput per berth) can be established.

Table 3. Distribution of critical factors derived from DEA-CCR for each port

\begin{tabular}{|c|c|c|c|c|c|c|c|c|c|c|c|}
\hline $\begin{array}{l}\text { Input } \\
\text { variables }\end{array}$ & Port & $\begin{array}{l}\text { 옿 } \\
\text { 오 }\end{array}$ & 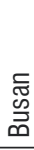 & $\begin{array}{l}\frac{\bar{d}}{N} \\
\frac{\bar{d}}{\bar{N}} \\
\frac{1}{\omega}\end{array}$ & $\begin{array}{l}\text { 음 } \\
\text { 들 }\end{array}$ & 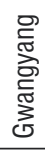 & $\begin{array}{l}\overline{0} \\
\text { 든 } \\
\text { 드 }\end{array}$ & 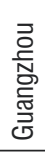 & $\begin{array}{l}\text { 듕 } \\
\stackrel{\mathscr{D}}{丂}\end{array}$ & 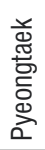 & Е \\
\hline YA/Berth & & 1 & 0 & 1 & 0 & 0 & 0 & 0 & 0 & 0 & 2 \\
\hline QC/Berth & & 1 & 0 & 1 & 1 & 0 & 0 & 0 & 0 & 0 & 3 \\
\hline TC/Berth & & 2 & 1 & 1 & 0 & 2 & 0 & 1 & 0 & 0 & 7 \\
\hline YT/Berth & & 1 & 6 & 0 & 2 & 3 & 2 & 0 & 1 & 1 & 16 \\
\hline BL/Berth & & 0 & 0 & 0 & 0 & 0 & 0 & 0 & 0 & 0 & 0 \\
\hline
\end{tabular}

With respect to obtaining a regression model summary with the backward elimination method, the $\mathrm{R}$-squared value or correlation coefficient, ranges from 0.812 to 0.843 , and the adjusted R-squared, which is the adjusted coefficient of determination, ranges from 0.797 to 0.807 . This indicates the independent variables $\mathrm{YA}, \mathrm{QC}, \mathrm{TC}, \mathrm{YT}$ and $\mathrm{BL}$ explain the regression analysis model as having a good fit. Accordingly, the RA model shows remarkable statistical significance, as can be seen in Table 5 . The independent variables have been excluded from Models 1 to 4 in the following order: YA from Model 2, BL and YA from Model 3, and QC, BL and YA from Model 4, which suggests that YT and TC are the most important variables. The standard error of the estimate is also given, which indicates a measure of the accuracy of predictions.

Other statistics have also been used to evaluate the critical factors at a container terminal. Using ANOVA analysis, we have also applied four models

Table 4. Port efficiency statistics derived from DEA-CCR for each port

\begin{tabular}{|c|c|c|c|c|c|c|c|c|c|}
\hline Statistics $\quad$ Port & Hong Kong & Busan & Shenzhen & Ningbo & Gwangyang & Incheon & Guangzhou & Ulsan & Pyeongtaek \\
\hline No. of cont. term. & 5 & 7 & 3 & 3 & 5 & 2 & 1 & 1 & 1 \\
\hline No. of effic. port & 1 & 0 & 1 & 1 & 0 & 0 & 0 & 0 & 0 \\
\hline Maximum value & 1 & 1 & 1 & 1 & 0.93 & 0.66 & 0.66 & 0.65 & 1 \\
\hline Minimum value & 0.71 & 0.47 & 0.69 & 0.73 & 0.15 & 0.06 & 0.61 & 0.38 & 0.95 \\
\hline Mean value & 0.9576 & 0.8106 & 0.8713 & 0.9147 & 0.4352 & 0.353 & 0.644 & 0.596 & 0.99 \\
\hline Standard Deviation & 0.0447 & 0.1649 & 0.1320 & 0.1270 & 0.2869 & 0.3960 & - & - & - \\
\hline
\end{tabular}


with the elimination method and calculated the sum of squares and mean square values. From Table 6, the significant probability is always equal to 0.00 in applying independent variables removed in an orderly manner (as in the case of Table 5). In contrast, the F-test analyses the overall regression of the model and reflects satisfied results, which are also summarized. ANOVA analysis results show that the most significant independent variables are YT and TC.

Table 5. Regression model summary

\begin{tabular}{ccccc}
\hline Model & R & R-Squared & $\begin{array}{c}\text { Adjusted } \\
\text { R-Squared }\end{array}$ & $\begin{array}{c}\text { Std. Error of } \\
\text { the Estimate }\end{array}$ \\
\hline 1 & $0.918(\mathrm{a})$ & 0.843 & 0.807 & 108471.3905 \\
\hline 2 & $0.917(\mathrm{~b})$ & 0.840 & 0.812 & 107046.0609 \\
\hline 3 & $0.910(\mathrm{c})$ & 0.828 & 0.806 & 108838.2806 \\
\hline 4 & $0.901(\mathrm{~d})$ & 0.812 & 0.797 & 111440.0392 \\
\hline
\end{tabular}

Note: (a) Predictors: (Constant), BL, YT, YA, TC, QC; (b) Predictors: (Constant), BL, YT, TC, QC; (c) Predictors: (Constant), YT, TC, QC; (d) Predictors: (Constant), YT, TC

Table 6. ANOVA analysis results

\begin{tabular}{|c|c|c|c|c|c|}
\hline & Model & $\begin{array}{l}\text { Sum of } \\
\text { Squares }\end{array}$ & $\begin{array}{l}\text { Mean } \\
\text { Square }\end{array}$ & F-test & Sig. \\
\hline & Regression & 1.390E12 & $2.780 \mathrm{E} 11$ & 23.6 & $0.000 \mathrm{a}$ \\
\hline \multirow[t]{3}{*}{1} & Residual & $2.589 \mathrm{E} 11$ & 1.177E10 & & \\
\hline & Total & $1.649 \mathrm{E} 12$ & & & \\
\hline & Regression & $1.386 \mathrm{E} 12$ & 3.464E11 & 30.2 & $0.000 \mathrm{~b}$ \\
\hline \multirow[t]{3}{*}{2} & Residual & $2.636 \mathrm{E} 11$ & $1.146 \mathrm{E} 10$ & & \\
\hline & Total & $1.649 \mathrm{E} 12$ & & & \\
\hline & Regression & 1.365E12 & 4.549E11 & 38.4 & $0.000 \mathrm{c}$ \\
\hline \multirow[t]{3}{*}{3} & Residual & $2.843 \mathrm{E} 11$ & $1.185 \mathrm{E} 10$ & & \\
\hline & Total & $1.649 \mathrm{E} 12$ & & & \\
\hline & Regression & 1.339E12 & 6.693E11 & 53.9 & $0.000 \mathrm{~d}$ \\
\hline \multirow[t]{2}{*}{4} & Residual & $3.105 \mathrm{E} 11$ & $1.242 \mathrm{E} 10$ & & \\
\hline & Total & $1.649 \mathrm{E} 12$ & & & \\
\hline
\end{tabular}

Note: (a) Predictors: (Constant), BL, YT, YA, TC, QC; (b) Predictors: (Constant), BL, YT, TC, QC; (c) Predictors: (Constant), YT, TC, QC; (d) Predictors: (Constant), YT, TC

The same four models have been analysed using coefficient analysis. Applying that and the T-test, which tests the single variable significance of the model, also reflect satisfied results. It shows that the $\mathrm{BL}$ variable has a negative impact on the dependent variable (throughput per berth). Similarly, the standardized coefficients' Beta value appears minus the value for the variable BL. It means that, as throughput per berth increasing, the independent variable berth length would not be appropriate to handle this increased throughput. This implies that in this case $\mathrm{BL}$ is a critical factor for container terminals. However, the significant probability is decreasing, which suggest that variables YT and TC have the main impact on reaching throughput per berth. The results are summarized in Table 7.

Table 7. Coefficients analysis results

\begin{tabular}{|c|c|c|c|c|c|}
\hline & Model & $\begin{array}{c}\text { Ustd. } \\
\text { Coefficients }\end{array}$ & $\begin{array}{l}\text { Beta } \\
\text { value }\end{array}$ & T-test & Sig. \\
\hline \multirow{6}{*}{1} & (Constant) & -75592.627 & & -0.490 & 0.629 \\
\hline & YA & 0.233 & 0.059 & 0.632 & 0.534 \\
\hline & $Q C$ & 92825.355 & 0.325 & 1.705 & 0.102 \\
\hline & TC & 34056.108 & 0.492 & 3.260 & 0.004 \\
\hline & $\mathrm{YT}$ & 5679.013 & 0.238 & 1.774 & 0.090 \\
\hline & $\mathrm{BL}$ & -765.770 & -0.150 & -1.470 & 0.156 \\
\hline \multirow{5}{*}{2} & (Constant) & -65849.041 & & -0.434 & 0.668 \\
\hline & QC & 85529.610 & 0.300 & 1.628 & 0.117 \\
\hline & TC & 34277.077 & 0.496 & 3.327 & 0.003 \\
\hline & $\mathrm{YT}$ & 6010.075 & 0.252 & 1.929 & 0.066 \\
\hline & $\mathrm{BL}$ & -632.240 & -0.120 & -1.350 & 0.192 \\
\hline \multirow{4}{*}{3} & (Constant) & -232134.707 & & -2.590 & 0.016 \\
\hline & QC & 79042.594 & 0.277 & 1.486 & 0.150 \\
\hline & TC & 32715.465 & 0.473 & 3.143 & 0.004 \\
\hline & $\mathrm{YT}$ & 5905.614 & 0.248 & 1.864 & 0.075 \\
\hline \multirow{3}{*}{4} & (Constant) & -133732.596 & & -2.180 & 0.039 \\
\hline & $\mathrm{TC}$ & 43582.420 & 0.630 & 5.745 & 0.000 \\
\hline & $\mathrm{YT}$ & 8693.668 & 0.365 & 3.327 & 0.003 \\
\hline
\end{tabular}

Finally, results from regression show that, in the scope of the independent variables, the numbers of YT and TC have a strong impact on berth productivity. The regression formulation, which is composed of the number of yard tractors and terminal cranes is:

$$
Y=-133732.596+43582.420 X_{1}+8693.668 X_{2},
$$

where $X_{1}$ is the number of terminal cranes (TC) while $X_{2}$ represents the number of yard tractors (YT).

\section{IMPLICATIONS AND COMPARISON}

The empirical results from DEA-CCR and RA analyses show that the input/independent variables for determining the critical factors at container terminals have a great contribution to terminal productivity. It is clear that the significance of critical factors for productivity is similar in respect to the chosen container terminals. The results indicate the first implication that the most important of factors are TC and YT. Table 8 shows the order of significance for the critical factors derived from both analyses. Obviously, both models affirm the importance of a number of terminal cranes and yard tractors.

Another implication of the results achieved in the analyses is that the facilities of a container terminal, 
such as YA and BL, appear to exhibit lower levels of significance than the equipment. Although it is shown that huge YA or long BL do not always imply the higher productivity of terminals, it indicates that if the number of handling equipment like TC and YT were increased, the container terminal could improve its productivity.

Table 8. Order of significance for critical factors derived from DEACCR and RA analyses

\begin{tabular}{|c|c|c|c|}
\hline 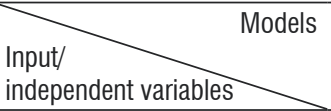 & $\begin{array}{l}\text { DEA-CCR } \\
\text { order of } \\
\text { sign. }\end{array}$ & $\begin{array}{l}\text { RA } \\
\text { order of } \\
\text { sign. }\end{array}$ & $\begin{array}{l}\text { Output/ } \\
\text { dependent } \\
\text { variable }\end{array}$ \\
\hline YA & 3 & 5 & \multirow{5}{*}{$\begin{array}{c}\text { Throughput } \\
\text { per berth }\end{array}$} \\
\hline$Q C$ & 4 & 3 & \\
\hline TC & 1 & 1 & \\
\hline $\mathrm{YT}$ & 2 & 2 & \\
\hline $\mathrm{BL}$ & 5 & 4 & \\
\hline
\end{tabular}

In relation to the DEA-CCR model, the YA variable is in third place, with $\mathrm{QC}$ following. BL represents the input variable with the lowest level of significance. According to the coefficient results of $\mathrm{RA}$, in the scope of the independent variables, the number of YT, TC and QC have a stronger impact on the throughput per berth. The YA also has a positive correlation, but in contrast, berth length has a negative correlation.

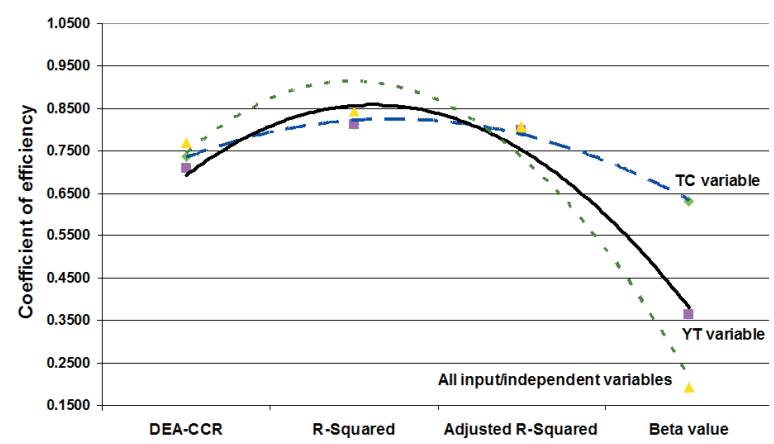

Fig. 5. Comparison of coefficients of efficiency for input/ independent variables (two different models)

Next, we compared the coefficients of efficiency for TC, YT and all input/independent variables in respect to different models (DEA-CCR, R-Squared, Adjusted R-Squared and Beta value as models of RA). The trend lines are shown in Fig. 5. The results for R-Squared imply the highest efficiency of container terminals with $0.8120,0.8120$ and 0.8430 for TC, YT and all input/independent variables, respectively. Next are the Adjusted R-Squared results of efficiency with $0.7970,0.7970$ and 0.8070 for the same variables, respectively. DEA-CCR proposes the efficiencies of
0.7368, 0.7075 and 07686 for TC, YT and all input/ independent variables, respectively. Finally, the Beta value gives the lowest results with $0.6300,0.3650$ and 0.1928 for the same variables, respectively.

According to the results of both analyses, the following conclusions can be drawn. The higher the numbers of $\mathrm{TC}$ and $\mathrm{YT}$, the higher the berth productivity will be. With respect to BL which has a negative correlation to throughput per berth, the increase of BL leads to a decrease in productivity. In contrast, YA differs from one case to another. For example, the yard area of the COSCO container terminal in Hong Kong is 20 ha and the throughput per berth is 700,000 TEU while the yard area of the HBCT container terminal in Busan is $25.2 \mathrm{ha}$, and the throughput per berth is $600,000 \mathrm{TEU}$. In contrast with the container terminals of the Republic of Korea, the yard area of Chinese ports is much larger. However, the reason the YA is not selected as an effective independent variable is that most container terminals use an off-dock container YA to improve yard utilization and rapid response to customers. The same assumptions are drawn with the average number of QC. Again, if comparing COSCO and HBCT container terminals, the average number of $\mathrm{QC}$ that are used at terminals for the first one is 3.6 while for the second is 3.3. COSCO reached 700,000 TEU per berth while HBCT reached 600,000 TEU per berth in 2008. It is a massive difference in total throughput even though the average number of QC at both container terminals is similar. This means that the number of $\mathrm{QC}$ is not related to the throughput directly.

\section{CONCLUSIONS}

This study proposes DEA-CCR and RA models to assess the sensitivity analysis for identifying critical factors of productivity for container terminals. The sensitivity analysis shows that the input/independent variables for determining the critical factors at container terminals make a great contribution to terminal productivity. The sensitivity of an input or output measure is defined as the range of changes of the input or output measure to improve the efficiency of the frontier. The most sensitive factors are denoted as critical for considered container terminals. The empirical results indicated that the most important of them are TC and YT in the container terminals' efficiency evaluation of the 28 chosen terminals in nine ports. These results have provided useful information indicating how relatively inefficient container terminals can improve their efficiency. 
As a benchmarking analysis, this study provides the two different approaches to efficiency measurement of container terminals, DEA-CCR and RA and compares their efficiency. These methods are applied to the same data set, and sensitivity analysis is conducted to compare the results of critical factors at container terminals. The productivity of a container terminal is influenced by a range of factors, which were removed one by one, and the correlation between productivity and investment then re-estimated.

Furthermore, another major objective of this study was to compare the results obtained from applying DEA-CCR and RA. It is important to note some advantages of DEA-CCR over RA being as follows: DEA-CCR measures performance against efficient rather than average performance, DEA-CCR offers more accurate estimates of relative efficiency because it is a boundary method; DEA-CCR normally yields more accurate targets because it is a boundary method, and so on. However, some advantages of RA over DEA-CCR may be summarised as: RA offers a better predictor of future performance at the collective DMU level if it is assumed inefficiencies cannot be eliminated, RA offers the facility to estimate confidence intervals for point estimates, and RA could yield better estimates of individual maximum (minimum) levels where outputs (inputs) can vary independently of one another, among others [17] to [20].

Moreover, there are also some limitations of the research. Several factors of terminal productivity are not included in the variables, such as the number of vessel arrivals, manpower, the service time of vessels, and so on. However, the acquisition of data is quite difficult, and the combinations of independent/input variables and dependent/output variables that are utilized in this study also have to be adjusted.

In further research, this study will enlarge the number of terminals and variables. The individual terminal simulation model will represent the direction for future investigations.

\section{ACKNOWLEDGEMENTS}

The study is supported by Liaoning Provincial Education Department (LPED) and a Tongmyong University Research Grant. The study is also financially supported by the LPED Project (W2012246), LPE and Science "Twelfth Five" Planning 2012 Project (JG12DB345), MOMAF (Ministry of Maritime and Fishery Affairs) Republic of Korea, through the "Evaluation of Port Capacity" project of the University.

\section{REFERENCES}

[1] Tongzon, J., Heng, W. (2005). Port privatization, efficiency and competitiveness: some empirical evidence from container ports. Journal of Transportation Research A: Policy and Practice, vol. 39, no. 5, p. 405-424, DOI:10.1016/j.tra.2005.02.001.

[2] Le-Griffin, H.D., Murphy, M. (2006). Container port productivity: experiences at the ports of Los Angeles and Long Beach. METRANS 2006 Conference Proceedings, p. 1-21.

[3] Cullinane, K., Wang, T.F., Song, D.W. (2006). The technical efficiency of container ports: Comparing data envelopment analysis and stochastic frontier analysis. Journal of Transportation Research Part A, vol. 40, p. 354-374, DOI:10.1016/j.tra.2005.07.003.

[4] Park, N.K., Kim, J.Y., Lu, B. (2008). Critical factors for container port productivity. Proceedings of International Association of Maritime Economists, p. 262-272.

[5] Park, N.K., Lu, B. (2010). A study on productivity factors of Chinese container ports. Journal of Korean Navigation and Port Research, vol. 34, no. 7. p. 559566, DOI:10.5394/KINPR.2010.34.7.559.

[6] Lu, B., Park, N.K. (2010). Operational performance evaluation of Korean major container terminals. Journal of Korean Navigation and Port Research, vol. 34, no. 9, p. 719-726, DOI:10.5394/ KINPR.2010.34.9.719.

[7] Lu, B., Huo, Y.F., Park, N.K. (2012). A study on logistics requirements potential model based on spatial economics. Proceedings of XX. International Conference on Material Handling, Constructions and Logistics, p. 351-356.

[8] Yap, W.Y., Lam, J.S.L., Cullinane, K. (2011). A theoretical framework for the evaluation of competition between container terminal operators. Singapore Economic Review, vol. 56, no. 4, p. 535559, DOI:10.1142/S0217590811004456.

[9] Roll, Y., Hayuth, Y. (1993). Port performance comparison applying data envelopment analysis (DEA). Maritime Policy and Management, vol. 20, no. 2, p. 153-161, DOI:10.1080/03088839300000025.

[10] Itoh, H. (2002). Efficiency changes at major container ports in Japan: A window application of data envelopment analysis. Review of Urban and Regional Development Studies, vol. 14, no. 2, p. 133-152, DOI:10.1111/1467-940X.00052.

[11] Barros, C.P., Athanassiou, M. (2004). Efficiency in European seaports with DEA: Evidence from Greece and Portugal. Maritime Economics and Logistics, vol. 6, no. 2, p. 122-140, DOI:10.1057/palgrave. mel.9100099.

[12] Cullinane, K.P.B., Wang, T.F. (2007). Data envelopment analysis (DEA) and improving container port efficiency. Brooks, M., Cullinane, K.P.B. (eds.) Devolution, port governance and port performance, 
Research in Transportation Economics, vol. 17, p. 517-566, Elsevier, Amsterdam.

[13] Cullinane, K., Wang T.F. (2010). The efficiency analysis of container port production using DEA panel data approaches. OR Spectrum, vol. 32, no. 3, p. 717738, DOI:10.1007/s00291-010-0202-7.

[14] Lin, L.C., Tseng, C.C. (2007). Operational performance evaluation of major container ports in the Asia-Pacific region. Journal of Maritime Policy and Management, vol. 34, no. 6, p. 535-551, DOI:10.1080/03088830701695248.

[15] Wu, J., Yan, H., Liu, J. (2009). Groups in DEA based cross-evaluation: An application to Asian container ports. Maritime Policy \& Management, vol. 36, no. 6, p. 545-558, DOI:10.1080/03088830903346095.

[16] Wu, J., Yan, H., Liu, J. (2010). DEA models for identifying sensitive performance measures in container port evaluation. Maritime Economics \& Logistics, vol. 12, no. 3, p. 215-236, DOI:10.1057/ mel.2010.6.

[17] Bowlin, W.F., Charnes, A., Cooper, W.W. (1985). Data Envelopment Analysis and regression approaches to efficiency estimation and evaluation. Annals of Operations Research, vol. 2, p. 113-138, DOI:10.1007/BF01874735.

[18] Thanassoulis, E. (1993). A comparison of Regression Analysis and Data Envelopment Analysis as alternative methods for performance assessments. Journal of Operational Research Society, vol. 44, no. 11, p. 1129-1144, DOI:10.1057/jors.1993.185.

[19] Cubbin, J., Tzandikas, G. (1998). Regression versus data envelopment analysis for efficiency measurement: an application to the England and Wales regulated water industry. Utilities Policy, vol. 7, no. 2, p. 75-85, DOI:10.1016/S0957-1787(98)00007-1.

[20] Klimberg, R.K., Lawrence, K.D. Yermish, I., Lal, T., Mrazik, D. (2009). Using regression and Data Envelopment Analysis (DEA) to forecast bank performance over time. In Lawrence, K.D., Kleinman, G. (eds.) Financial Modeling Applications and Data Envelopment Applications (Applications of Management Science, vol. 13, Emerald Group Publishing Limited, p. 133-142.

[21] Charnes, A., Cooper, W.W., Rhodes, E. (1978). Measuring the efficiency of decision making units, European Journal of Operational Research. vol. 2, no. 6, p. 429-444, DOI:10.1016/0377-2217(78)901388.

[22] Kleinbaum, D.G., Kupper, L.L., Muller, K.E, Nizam, A. (2007). Applied regression analysis and other multivariable methods. Thomson Higher Education, Belmont.

[23] Cicek, A., Kivak, T., Samtas, G., Cay, Y. (2012). Modeling of thrust forces in drilling of AISI 316 stainless steel using artificial neural network and multiple regression analysis. Strojniški vestnik Journal of Mechanical Engineering, vol. 9, no. 7-8. p. 492-498, DOI:10.5545/sv-jme.2011.297.

[24] Lu, B., Wang, X.L. (2012). Comparative studies on efficiency evaluation of Chinese and Korean major container terminals. Journal of Advances in Information Sciences and Service Sciences, vol. 56, p. 645-654. 